\title{
Health Policy and Management
}

\section{Correspondence}

\section{Food Taxes: How Likely Are Likely Effects?}

\section{Ignaas Devisch*}

Artevelde University College, University of Ghent, Belgium

Received: 22 August 2013, Accepted: 26 August 2013, ePublished: 27 August 2013

$\mathrm{I}$ want to thank Block and Willett (1) for their comments on my paper (2). Their remarks are substantial, thoughtful and they help us to discuss more profoundly one example of a food tax, the tax on Sugar-Sweetened Beverages (SSBs). Indeed, not all food taxes are created equal and next to a more general debate, we need to discuss into details every kind of attempt to tackle the increasing prevalence of obesity and diabetes. Though SSBs were not in particular what I had in mind, of course they are included in the debate.

Let me reply to some of their arguments, given the limited word count of this format. I want to apologize for not being able to get into all of the arguments.

The "strong evidence" Block and Willett relied upon, needs careful interpretation. Looking after evidence on the effects of taxes, it is almost exclusively based on simulation studies which only predict ('likely effect') and therefore inherently neglect the complexity of real life situations. As Hawkes has demonstrated (3), current evidence does not leave the uncertainty behind us. While we are talking about the complex cross-section of many areas and disciplines, the awareness of this complexity seems to be absent in their suggestions. They righteously stated that "no policy is viewed in isolation" but looking after arguments, they quoted many trials which did isolate the topic of SSBs to predict the effect.

We should be very careful in interpreting predictions. Duffey et al., in a longitudinal study that laid bare some tendencies but with modest conclusions which was quoted by the Block and Willett, explicitly warned the reader for hasty conclusions: "Although price policies, such as taxation, are beginning to be used as a means of addressing obesity, diabetes, and other nutrition-related health concerns, minimal research has been done to study how these price changes would have an impact on health outcomes (4)." Also Lin et al. warned us not to forget the complexity of real world consumption strategies (5). Obese groups, for instance, respond less to changes in price relative to people with healthy weights, to mention only one aspect (6). Others warn us that, despite the evidence, the decrease of consumption of SSBs, the testing effect is often weak (7).

Though a potential means to counter health problems, often food taxes discriminate because they are equal for all. The difficulty of food taxes is that they tax on consumption while overconsumption often is the problem, next a complete lack of physical activity. Of course, some food has almost no nutritional value, but we should also think of for instance a marathon runner: he or she needs SSBs to recover from many miles. Why should someone with a healthy lifestyle be discriminated?
And if we exclude sports drinks from the taxes, then we have a perfect substitution for SSBs, a problem Block and Willett seem to minimalize.

If I referred to taxes as a new holy grail, I particularly had in mind the recent initiatives in many European countries, where food taxes are used to solve state deficits. Taxes can only be introduced when all other strategies have failed. Next to prevention and education-which are still underused means to tackle health problems-, e.g. offering a systematic alternative to SSBs (free tap water) is a serious option when it comes down to rather isolated environments such as schools, offices, etc (8). Evidently, when based in strong evidence and implemented in a socially non-discriminative way, taxes on SSBs could be of help as just one measure in the global fight against noncommunicable diseases.

\section{Ethical issues \\ Not applicable.}

\section{Competing interests}

The author declares no competing interests.

Author's contribution

ID is the single author of the manuscript.

\section{References}

1. Block J, Willett W. Taxing Sugar-Sweetened Beverages: Not a "Holy Grail" but a Cup at Least Half; Comment on "Food Taxes: A New Holy Grail? International Journal of Health Policy and Management 2013; 1 : 183-5.

2. Devisch I. Food taxes: a new holy grail? International Journal of Health Policy and Management 2013; 1: 95-7.

3. Hawkes C. Food taxes: what type of evidence is available to inform policy development? Nutr Bull 2012; 37: 51-6.

4. Duffey KJ, Gordon-Larsen P, Shikany JM, Guilkey D, Jacobs DR, Popkin BM. Food price and diet and health outcomes: 20 years of the CARDIA study. Arch Intern Med 2010; 170: 420-6.

5. Lin BH, Smith TA, Lee JY, Hall KD. Measuring weight outcomes for obesity intervention strategies: the case of a sugar-sweetened beverage tax. Econ Hum Biol 2011; 9: 329-41.

6. Epstein LH, Dearing KK, Paluch RA, Roemmich JN, Cho D. Price and maternal obesity influence purchasing of low- and high-energy-dense foods. Am J Clin Nutr 2007; 86: 914-22.

7. Kaiser KA, Shikany JM, Keating KD, Allison DB. Will reducing sugarsweetened beverage consumption reduce obesity? Evidence supporting conjecture is strong, but evidence when testing effect is weak. Obes Rev 2013; 14: 620-33.

8. Public health law \& policy. Bringing Free Drinking Water Back to California Schools. [cited 2013 August 20]. Available from: http:// changelabsolutions.org/publications/bringing-free-drinking-water-backcalifornia-schools 